DOI: https://doi.org/10.11144/Javeriana.upsy18-4.emee

\title{
Entre milagros, espíritus y esoterismo: pensamiento mágico y pseudociencia en el Chile globalizado del siglo XXI *
}

\section{Among Miracles, Spirits and Esotericism: Magical Thinking and Pseudoscience in the Globalized Chile the XXI Century}

Recepción: 04 Enero 2018 | Aceptación: 02 Noviembre 2019

\author{
Carlos Rodríguez Garcés ${ }^{\mathrm{a}}$ \\ Universidad del Bío-Bío, Chile \\ ORCID: http://orcid.org/0000-0002-9346-0780 \\ Mónica Valenzuela Orrego \\ Universidad del Bío-Bío, Chile \\ ORCID: http://orcid.org/0000-0003-3330-5786
}

a Autor de correspondencia. Correo electrónico: carlosro@ubiobio.cl

Para citar este artículo: Rodríguez Garcés, C., \& Valenzuela Orrego, M. (2019). Entre milagros, espíritus y esoterismo: pensamiento mágico y pseudociencia en el Chile globalizado del siglo XXI. Universitas Psychologica, 18(4), 1-13. https:// doi.org /10.11144/Javeriana.upsy18-4.emee

\section{RESUMEN}

Paralelo a la racionalidad que sustenta la ciencia y la tecnología, persiste un conjunto de creencias infundadas entre la ciudadanía, las que usualmente omiten criterios científicos para dar explicación a fenómenos aparentemente sobrenaturales. Haciendo uso de los datos de la primera Encuesta nacional de percepción social de la ciencia y la tecnología (EPSCYT) aplicada en Chile el año 2016, se exploran descriptivamente mediante prevalencias y razones de probabilidad, algunos fenómenos en los que la gente cree, y se analiza qué tan arraigados están en los diversos segmentos de la población. Entre los resultados, encontramos una alta prevalencia en creencias acerca de la existencia de los milagros (79\%), los espiritus (65\%), la telepatía (60.2\%), la numerología (50.4\%) y los OVNIS (59.9\%). Como discusión, se plantea una paradoja de la modernidad, donde pese a la propagación del conocimiento científico y las tecnologías, algunas creencias en lo sobrenatural se mantienen, esto incluso entre quienes teóricamente serían más escépticos, es decir, quienes han alcanzado educación universitaria, son adultos, se declaran agnósticos y/o partidarios de la tesis de comprobabilidad.

Palabras clave

creencias infundadas; pseudociencia; pensamiento mágico; ciencia y tecnología; percepción social.

\section{ABSTRACT}

Parallel to the rationality underpinning current science and technology, a set of unfounded beliefs persists among citizens who generally omit scientific criteria to give explanation to seemingly supernatural phenomena. Using the data from the first "National Survey of Social Perception of Science and Technology" (EPSCYT) applied in Chile in 2016, some phenomena in which people believe are explored descriptively and using reasons of probability, and It is analyzed how entrenched they are in the various segments of the population. Among the results, we found a high prevalence in beliefs about the existence of miracles (79\%), the spirits (65\%), the telepathy (60.2\%), numerology $(50.4 \%)$ and UFO's (59.9\%). The discussion raises a paradox of modernity, where 
despite the propagation of scientific knowledge and technologies, some beliefs in the supernatural are maintained, this even among those who would theoretically be more skeptical, i.e. who have Attained university education, they are adults, they declare themselves agnostics and/or supporters of the thesis of the verification.

Keywords

unfounded beliefs; pseudoscience; magical thinking; science and technology; social perception.

Las personas nunca son plenamente autónomas, su accionar en el mundo, y la forma de verlo, está determinado por sistemas de creencias compartidos y heredados que actúan como condicionantes para la toma de decisiones y el desarrollo de actividades a lo largo de la vida. Las creencias son producto de un aprendizaje y, aunque mutables, nos delimitan social y culturalmente en un tiempo y lugar (Meléndez, 2016), representando un factor básico en la articulación decisional y comportamental (Blanco, Ornelas, Aguirre, \& Guedea, 2012).

Ontológicamente, las creencias son parte constitutiva de lo que llamamos realidad o idea de mundo y, por su carácter colectivo e históricamente dado, se les suele sobreañadir al canon de referencia de corte adventicio, componentes imaginarios que las transforman en creencias supersticiosas, las que son representadas y socializadas mediante el lenguaje y la imitación. Toda creencia, en tanto conducta lingüística emitida, supone un logos y una razón, en consecuencia, toda creencia sería racional, a pesar del reducido o nulo grado de exactitud que pueda corresponderle con la verdad. No obstante, desde la psicología cognitiva se informa de la existencia de creencias ilógicas e irracionales, en tanto derivaciones imprecisas de la realidad tomadas como verdades, que se sostienen en contra y a pesar de la evidencia reconocida (Taylor \& Kowalski, 2004); refieren a un conjunto de ideas que, a diferencia de la establecidas por la ciencia, son cerradas, no contrastables, carentes de método y de valor factual (Iglesias, 2012).

La creencia se puede basar en la realidad, pero no es la realidad. Su propia naturaleza relativa y su particular carácter subjetivo tienden a ser una consistente limitación a la comprensión total y última del mundo en que se vive y que se busca entender. Los seres humanos necesitan operar dentro de espacios de certidumbre, un mundo organizado donde los fenómenos y los acontecimientos tengan explicación, necesidad que los ha aproximado tempranamente a las creencias irracionales, el pensamiento mágico y la intervención de los dioses por ser lo más accesible e inmediato frente a la necesidad de comprender fenómenos complejos y dar explicación a eventos extraordinarios (Damisch, 2008; Guerrero, Ávila, \& Miranda, 2008; Iglesias, 2012).

Desde la antropología cultural y su relativismo, se expone que la acción social se encuentra preconfigurada contextualmente de forma tal que lo considerado racional por unas personas sería conceptualizado como absurda o ridícula por otras, de allí la necesidad de valorar diferenciadamente las normas sociales idiosincráticas. No obstante, determinadas creencias son susceptibles de ser expuestas a una valoración crítica. La mera existencia de facto de diferentes normas sociales en distintos grupos humanos no da pie a reivindicar el relativismo moral o cognoscitivo, ni menos que estas ideas no puedan ser criticadas desde el punto de vista de alguna norma universal. Es, por lo menos, una irresponsabilidad intelectual considerar que algo puede llegar a ser cierto simplemente porque es deseado; las ideas se validan y dejan de ser mera creencia porque transitan exitosamente por la examinación sistemática, dándole mayor peso a la evidencia consistente que al principio de autoridad.

Las creencias irracionales, en tanto carentes de sustento empírico, develarían ingenuidad o ignorancia, influenciada por la costumbre, el prejuicio popular y la sumisión acrítica al principio de autoridad (Iglesias, 2012). Son, además, expresión de estructuras de pensamientos rígidos y dogmáticos que limitan la búsqueda de la verdad, y obstaculizan el desarrollo de la personalidad, al generar emociones y comportamientos disfuncionales, escasamente eficientes frente a la delimitación 
de problemas y a la definición de estrategias adecuadas para abordarlos (David, Lynn, \& Ellis, 2010), incluso estas mismas creencias convertidas en dogma oficial son antesala de la intolerancia social frente al disidente (Medrano, Galeano, Galera, \& Fernández, 2010).

Es deber de la ciencia no solo divulgar sus hallazgos y hacer luz sobre determinados misterios que permanecían sin resolver, sino además desarrollar un pensamiento crítico que combata la irracionalidad de ideas infundadas que, propagándose como virus pseudointelectuales, suponen un peligro para la seguridad personal y social (Iglesias, 2012). Con independencia relativa de la naturaleza del objeto y en razón de su procedimiento, la demarcación de la ciencia pueda trazar una línea divisoria clara entre lo que es conocimiento científico y especulación argumentativa, irracional o infundada. No obstante, y a pesar de la trascendencia que para la vida diaria tiene la ciencia y el desarrollo tecnológico que de este conocimiento se deriva, las creencias irracionales o infundadas prevalecen en un importante contingente de individuos.

Encontrándonos en la era de la decodificación del ADN, el descubrimiento de nuevas estrellas y sistemas solares a años luz, la comunicación instantánea, el desarrollo de la robótica y la inteligencia artificial, resulta contradictorio y desalentador que tal desarrollo científico no haya sido capaz de penetrar sistemas de creencias que sostienen aún la existencia de los milagros, la resurrección de los muertos, la magia y la predicción del futuro. Nos encontramos frente a la promesa de una ilustración frustrada o, cuando menos inconclusa, en cuanto a que la ciencia, en su ideal utilitario, estaba al servicio del bien común y podía develar los misterios del universo, destruyendo los mitos y fanatismos que obstaculizaban una mayor racionalidad en la sociedad humana (Cornejo, 2011).

No obstante su esencia comunicativa, el riguroso lenguaje utilizado por la ciencia y sus profesionales la escinde de la sociedad y del público no iniciado, generando un territorio de frontera llano para ser ocupado por los charlatanes y su bisutería (Gutiérrez, 2007). Los medios de comunicación, y más recientemente las redes sociales, son un gran vehículo para la difusión de las creencias irracionales, en un régimen político, social y cultural basado en la credulidad voluntaria (Garces, 2017). Las pseudociencias, la política, la publicidad y la religión se apoyan en su capacidad de penetración para influir en una audiencia ávida de escuchar la promesa de mejora de sus vidas (Suárez, 2016), aunque sea por medio de afirmaciones carentes de base empírica y racional (Orea, 2013). Es este respaldo y tribuna otorgada por los medios lo que hace florecer, expandir y perfeccionarse a las creencias irracionales. Los medios de comunicación, junto con garantizar un acceso democrático a la información, amplifican el potencial de la creencia y la insertan socialmente dada su capacidad estructurante sin contrapeso para normalizar conductas e imponer narrativas o posverdades sobre la realidad social, facilitando su interiorización por parte del público, lo que agrava sus amenazas y peligros (Molina, 2019). Rol paradojal toda vez que serían estos mismos medios los encargados de dar cobijo divulgativo a la ciencia, dada su declarada función deontológica social y educativa, contradicción que transgrede las mismas regulaciones éticas y acentúa su responsabilidad frente al crecimiento exponencial de creencias infundadas o pseudocientíficas (Alonso \& Cortiñas, 2014; Murillo, 2012).

Las creencias irracionales se propagan profusamente en el tejido social compitiendo por una cuota de legitimidad con la ciencia, cohabitando incluso en un mismo espacio institucional, como la escuela, a pesar de ser contradictorias e inconciliables. La teoría de la evolución darwiniana y la del diseño inteligente, como nueva conceptualización del creacionismo, son mucho más que distintas respuestas a una misma pregunta, como ilusoriamente se pretende hacer creer. Más bien, la propuesta de Darwin es una respuesta basada en la evidencia recurrentemente consistente, mientras la otra no pasa de ser una simple creencia especulativa.

En atención a lo anteriormente expuesto, no resulta extraño preguntarse cómo en sociedades 
que funcionan y se articulan en gran medida gracias al desarrollo de la ciencia y la tecnología, persistan y proliferen un conjunto de creencias irracionales e infundadas a pesar del mayor nivel educativo, socioeconómico y cultural de quienes las sustentan. En consecuencia, este artículo examina la prevalencia que tienen en la población chilena sistemas de creencias asociados a los espíritus, los milagros, la numerología, el acto de adivinación, los OVNIS y la telepatía, procurando develar el perfil de quien mantiene dicha creencia, así como los factores que inciden en su expresión y cuantía. Para ello, hace uso de la Encuesta nacional de percepción social de la ciencia y la tecnología (EPSCYT) aplicada por la Comisión Nacional de Investigación Científica y Tecnológica (CONICYT), durante los años 2015-2016.

\section{Método}

\section{Instrumento}

El artículo hace uso de la Encuesta nacional de percepción social de la ciencia y la tecnología (EPSCYT) realizada en Chile durante los años 2015-2016. La EPSCYT, responsabilidad de la Comisión Nacional de Investigación Científica y Tecnológica (CONICYT), busca establecer por primera vez una línea base para conocer el estado de situación en que se encuentra la sociedad chilena en su relación con la ciencia y la tecnología. EPSCYT, de representación nacional, fue aplicada a una muestra de 7637 personas mayores de 15 años, extraída probabilística y estratificadamente por áreas geográficas. A nivel nacional, presenta un error absoluto que transita desde el $+/-1.1 \%$ bajo el supuesto de muestreo aleatorio simple y un $+/-2 \%$ al incluir efectos de diseño, siempre dentro de un nivel de confianza del $95 \%$.

Se usaron las técnicas de "propensity score" para ajustes de no respuesta y "ranking" para ajustes posestratificación. En ambos casos, se usaron las variables de sexo, edad y religión para calcular la ponderación por factor de expansión. El trabajo de levantamiento de información aplicado mediante "paper and pencil interview" (PAPI) a las viviendas empadronadas, conllevó una tasa de respuesta del 74.6\% (RR1) y de rechazo del $11.1 \%$ (REF1).

\section{Participantes}

A nivel nacional, la muestra de 7637 personas está equilibrada por sexo (49,1\% son hombres), principalmente residentes de zonas urbanas $(87,1$ $\%)$, con relativa homogeneidad por rango etario de interés, donde el $56.7 \%$ no supera los 45 años. En su mayor parte, se declaran creyentes (87.4\%), principalmente católicos, con estudios básicos y medios (73.2\%).

\section{Tabla 1}

Características de la muestra

\begin{tabular}{llr}
\hline & Características (N=7637) & $(\%)$ \\
\hline Sexo & Hombre & 49.1 \\
& Mujer & 50.9 \\
Zona & Urbano & 87.1 \\
& Rural & 12.9 \\
Rango de & De 15 a 29 años & 30 \\
Edad & De 30 a 44 años & 26.7 \\
& De 45 a 59 años & 24.2 \\
& De 60 y más años & 19.1 \\
Religión & Religioso Practicante & 32.5 \\
& Religioso No Practicante & 55 \\
& Ateo o Agnóstico & 12.6 \\
Nivel & Media incompleta o inferior \\
Educacional & Media Completa & 35.5 \\
& Superior incompleta o superior & 37.6 \\
& Fuente: Elaboración propia \\
\hline & a partir de EPSCT (2016) \\
\hline
\end{tabular}

\section{Procedimiento}

El análisis estadístico se hizo sobre la base de las respuestas válidamente emitidas, excluyéndose las categorías no sabe y no responde, y siempre que la respuesta imputada no superara el $10 \%$ de la muestra. Junto con los contrastes descriptivos e inferenciales de comparación de proporciones, se realizó un análisis de regresión logística binomial a fin de conocer el peso o incidencia estadística que tiene para el sistema de creencias, explorado un conjunto de factores teóricamente relevantes, todo dentro de un nivel de confianza no inferior 
al $95 \%$. En lo específico, se exploraron las tasas de adscripción a la creencia en OVNIS, telepatía, numerología, la adivinación, los espíritus y los milagros, así como los atributos que inciden en dichas manifestaciones actitudinales referidos al sexo, zona de residencia, escolaridad, edad y religión.

\section{Resultados}

\section{Ideas irracionales en Chile}

La ciencia y el método científico son adquisiciones relativamente recientes de la humanidad, cuya impronta ha posibilitado un conocimiento cada vez más profundo y acabado de los otrora inexpugnables misterios de la naturaleza y del universo. Si bien queda mucho por conocer, el avance alcanzado en las últimas décadas es sorprendente y nos posiciona ventajosamente hacia un futuro teóricamente cada vez menos incierto, donde no tendrían cabida las oscuras fuerzas que en el pasado parecían regir el destino de hombres y mujeres. Mediante la duda metódica, la discusión sistemática y la experimentación, la ciencia procedimental busca desterrar las creencias infundadas, así como el oscurantismo y misticismo que de ellas se derivan, siendo rigurosa y selectiva respecto de lo que está dispuesta a admitir por cierto. No es que no tenga certidumbres fundamentales, al igual que las tiene el dogma, pero a diferencia de este, está dispuesta a revisarlas y dejar de creer en ellas cuando la mejor evidencia disponible no le sustenta.

\section{Figura 1}

Prevalencia de ideas irracionales en Chile (\%)

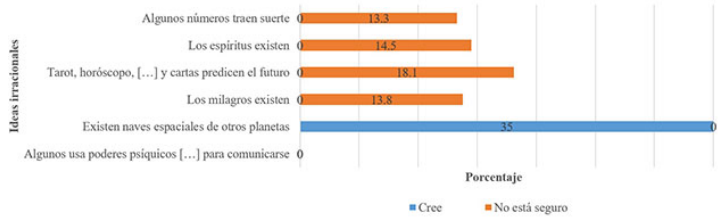

Fuente: Elaboración propia a partir de EPSCT (2016)
Así entendido, la ciencia es más que un conjunto de conocimientos útiles o utilizables, es por antonomasia una forma de pensar y de validar lo que se cree. A pesar de ello, en la actualidad vastos sectores, incluso profesionales de formación superior, tienden a dar valor a la ciencia con base a su mero rol instrumental y tecnológico dada su connatural capacidad para resolver problemas contingentes. La ciencia y su corriente divulgativa han sido escasamente eficientes en el objetivo de instalar, en el conjunto de las sociedades e individuos que la conforman, un modo de pensar, un procedimiento de pensamiento lógico que, siguiendo determinadas reglas y pasos, derive en una verdad provisional, la cual pueda someterse nuevamente a prueba de estimarse necesario. En efecto, y a pesar que siete de cada 10 sujetos señalen estar de acuerdo en que lo único cierto es aquello que se puede comprobar (73.6 \%), proporciones preocupantemente significativas manifiestan un alto nivel de adhesión respecto de creencias en un conjunto de fenómenos cuya existencia no ha sido demostrada por la ciencia, cuando no abiertamente negada.

La tesis de la modernidad sostenía la promesa de que la ciencia y la tecnología iban a ser capaces de solucionar los problemas humanos y satisfacer las necesidades básicas (Bauman \& Bordoni, 2016), haciendo, con ocasión de un mayor desarrollo cultural, prescindible la creencia irracional e infundada, el mito, e incluso la religiosidad, por cuanto estas no serían más que una mera necesidad antropológica de carácter primitivo ampliamente superada por el desarrollo. Promesa incumplida de la modernidad que, como resultado de la amenaza percibida que supone un desarrollo tecnológico descontrolado, incuba el temor y el recelo que da cobijo al florecimiento de una variopinta constelación de creencias y manifestaciones esotéricas, místicas e ilógicas, las cuales han adquirido evidente protagonismo en el mundo moderno (Beck, 2009; Iglesias, 2012).

Pese al estado de modernidad y desarrollo tecnológico evidenciado, la corriente mística de raigambre judeocristiana continúa siendo la teoría de la naturaleza humana más popular. Es 
así como un $79 \%$ de los chilenos manifiesta algún nivel de certeza respecto de la existencia de los milagros y un $65.2 \%$ cree en ellos abiertamente. Como rasgo cognoscitivo distintivo nos asiste la tendencia a buscar respuestas simples a problemas complejos, lo que facilita la incubación de ideas irracionales como son achacar la ocurrencia de determinados fenómenos a la intervención de los dioses, duendes o personajes extraterrestres (Fidanza \& Suárez, 2016; Gutiérrez, 2007). Tendencia que se fortalece al momento de buscar la explicación de la ocurrencia de eventos fortuitos y, amparados en el estado de vulnerabilidad, solicitar la colaboración de fuerzas cósmicas o intervención divina para propiciar el suceso deseado. No por casualidad un $65 \%$ cree en la existencia de los espíritus y un $50.5 \%$ lo sostiene con total seguridad.

Desde la tradición judeocristiana, el origen del universo y de los seres humanos estaría dada por la existencia de una divinidad, la cual no solo es arquitecta del mundo tal y como lo conocemos, sino que además es entidad omnisciente y reguladora de lo que ha creado. Con base a estas características y en concomitancia al libre albedrío, puede intervenir apiadándose de los seres humanos en su estadio de bondad y justicia infinita atribuida por los creyentes. Intervención que, mediante un hecho único y extraordinario, viola la lógica y las leyes de la naturaleza que la misma deidad ha establecido. La creencia en el milagro forma parte de una experiencia vital y fuerza operante en la vida de las personas que lleva a anidar dimensiones holísticas y cósmicas en sus matrices de sentido (Suárez, 2016). En situaciones que dejan patente la vulnerabilidad humana para resolver determinados problemas, se dirige la súplica mediante la oración, la ofrenda y el sacrificio hacia la divinidad o seres sagrados, solicitando su intervención para que actúen positivamente a nuestro favor (Castilla, 2011). En consecuencia, los milagros no solo se constituyen en una explicación al hecho inusual que no logramos comprender con la información disponible, sino que además, en tanto creencia, son expresión de una actitud particular de entender la vida y la naturaleza, un deseo y un anhelo que se manifiesta en razón de un estado de vulnerabilidad percibido. Deseo y necesidad que se acrecienta en experiencias existenciales adversas o traumáticas que ponen en cuestión la supervivencia, la felicidad y el bienestar (Frigerio \& Wynarczyk, 2013).

\section{Atributos vinculados a las creencias}

La creencia en los milagros no tan solo está fuertemente arraigada en la generalidad de los chilenos (79\%), sino que además su prevalencia estadística no reconoce grandes diferencias en razón de los atributos basales del sujeto.

\section{Tabla 2}

Tipos de creencias según atributos basales (\% Odds Ratio).

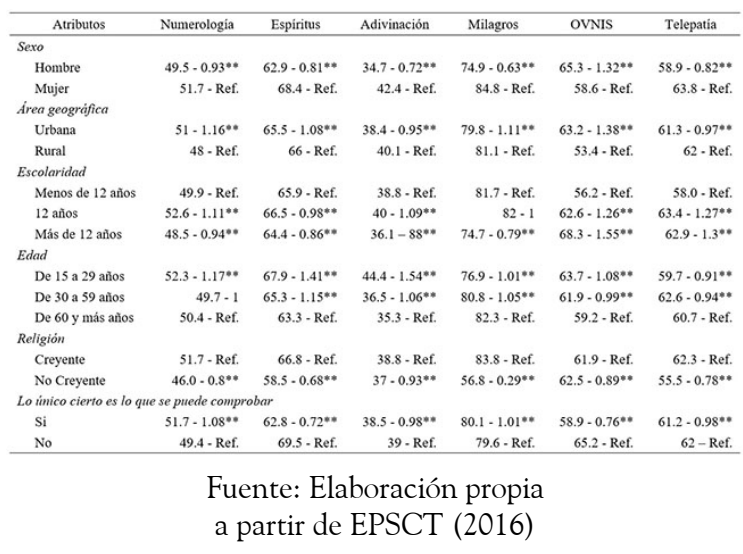

Si bien las proporciones se tienden a situar sobre el $75 \%$ de los consultados, estas son particularmente elevadas en las mujeres (84.8 $\%)$, en personas de menor escolaridad ( $82 \%$ ) y en quiénes se declaran creyentes $(83.8 \%)$, atributos que son refrendados al realizar un análisis de regresión logística. En efecto, en el contexto multivariante declararse agnóstico o ateo hace disminuir significativamente la probabilidad de creer en milagros $\left[\mathrm{EXP}_{(\beta)}=0.29 ; p<0.01\right]$ respecto de quien profesa alguna religión, sea en calidad de practicante o no. De igual forma lo hace el haber alcanzado un mayor nivel de escolaridad $\left[\operatorname{EXP}_{(\beta)}=0.79 ; p<0.01\right] \mathrm{y}$ ser de género masculino $\left[\mathrm{EXP}_{(\beta)}=0.63 ; p<\right.$ $0.01]$. Desde un punto de vista teórico, los hallazgos parecen consistentes toda vez que la 
literatura tiende a reconocer mayores niveles de credulidad y conservadurismo en personas que registran reducidos niveles educativos y en mujeres (Guerrero et al., 2008; Martín, 2016), aunque este último factor ha sido fuertemente modelado por el mayor acceso a la educación y al mercado del trabajo. A su vez, si bien parece lógicamente vinculante el creer en Dios y en los milagros, llama la atención que entre el contingente que se define como ateo o agnóstico, actualmente el $12.6 \%$ de la población consultada, uno de cada dos de ellos señalan que creen en los milagros (56.8\%), lo que supone una contradicción paradigmática relevante.

Pudiéndose aprobar, hasta cierto punto, que las leyes evolutivas y de la mecánica rigen sobre todos los ocupantes de un espacio, el reconocer que la naturaleza humana difiere solo en complejidad a otros seres animados, resulta de sumo difícil. Es complaciente aferrarse a la idea de que las personas estarían dotadas de una finalidad no banal y transcendente, siendo más que mera actividad eléctrica y química la que las hace sentir y pensar. Existiría un fantasma en la máquina que deriva del supuesto de que la mente estaría separada del cuerpo y puede sobrevivir una vez que el contenedor que la alberga deja de existir. Esta entidad inmaterial, llamada alma o espíritu, se presume puede compartir un mismo plano de existencia con los seres humanos, en particular, al ver eventualmente truncada su asunción a la dimensión que estaba predestinada.

La creencia en los espíritus es tan arraigada en Chile, en parte por la fuerte tradición cristiana, que solo un $35 \%$ no cree en su existencia. El sexo, la educación, la religión y la edad son factores que registran incidencia en la creencia en los espíritus dentro del análisis multivariante. El índice de credulidad disminuye cuando se es hombre [62.9 $\left.\% ;\left(\operatorname{EXP}_{(\beta)}=0.81 ; p<0.01\right)\right]$, se tiene más de 12 años de escolaridad [64.4\%; $\left(\mathrm{EXP}_{(\beta)}=0.86\right.$; $p<0.01)]$, se es agnóstico $\left[58.5 \%\left(\operatorname{EXP}_{(\beta)}=\right.\right.$ $0.68 ; p<0.01)$ ] y se confía en que lo único cierto es lo que se puede comprobar $\left[62.8 \%\right.$; $\operatorname{EXP}_{(\beta)}$ $=0.72 ; p<0.01)]$. No obstante, al constituirse estos atributos en factores protectores frente a la creencia en la existencia de los espíritus, llama la atención su alta prevalencia estadística que alcanza porcentajes generalmente superiores al $60 \%$. De igual modo a lo evidenciado al momento de analizar la creencia en los milagros, disponer de un mayor capital educativo, ser agnóstico e incluso tener un perfil actitudinal favorable hacia la tesis de la comprobabilidad, no inocula protectoramente respecto del sostener la infundada creencia en los espíritus, al menos no en la magnitud teóricamente presumible. Así mismo, llama la atención el comportamiento que tiene la edad, la cual conforme disminuye en rango hace aumentar la probabilidad de creer en espectros. Tomando como referencia el grupo de mayor edad, donde el $63.3 \%$ cree, en el rango etario de 30 a 59 años, lo hace un $65.3 \%$ [EXP $_{(\beta)}$ $=1.15 ; p<0.01]$, cifra que alcanza al $67.9 \%$ en el grupo de entre 15 a 29 años $\left[\operatorname{EXP}_{(\beta)}=1.41 ; p\right.$ $<0.01]$.

La alta prevalencia evidenciada en la creencia en los espíritus es un corolario de la idea del fantasma en la máquina o la teoría cartesiana de la dualidad, en donde existiría, por un lado, un cuerpo (res extensa) finito que requiere una coordenada temporoespacial, y por otro, un alma (res cogitans) incorpórea y eterna. Se trataría de un "soplo divino" del cual los seres humanos estaríamos hechos, gozando de idéntico atributo que el de su supremo inspirador, la inmortalidad espiritual. Esta creencia impulsa a crédulos, y eventualmente a escépticos, a la esperanza de una vida mejor en el más allá y a la idea de que quienes no han completado este tránsito, deambulan entre nosotros, pudiéndose establecer con ellos algún tipo de contacto, en particular, cuando se cuenta con los servicios de personas dotadas de "excepcionales capacidades" para leer la mente y comunicarse con los muertos (Shermer, 2008).

Es así como los datos informan que un $60.2 \%$ piensa que hay personas que usan poderes psíquicos o poseen un sexto sentido para comunicarse. Si bien, en todas las categorías de análisis, las proporciones de adhesión a la creencia en la telepatía es superior al $55 \%$, tienden a ser más abultadas para las mujeres $(63.8$ $\%)$, personas creyentes $(62.3 \%)$ y que superan los 12 años de escolaridad (62.9\%). El ser hombre $\left[58.9 \% ;\left(\operatorname{EXP}_{(\beta)}=0.82 ; p<0.01\right)\right]$ y ser Agnóstico [55.5\%; $\left.\left(\operatorname{EXP}_{(\beta)}=0.78 ; p<0.01\right)\right]$ 
se constituirían en factores protectores que hacen disminuir la probabilidad de sintonizar con este tipo de creencias. Especialmente paradójico, es el rol que juega la educación a este respecto, observándose que con un mayor nivel de escolaridad, contrario a lo que ha sido la tendencia respecto de otras creencias analizadas, aumenta la proporción y la probabilidad de creer en la telepatía, así como también en las naves extraterrestres visitantes.

Las creencias infundadas han sabido introducirse, replicarse y propagarse en el tejido social, manejando las nuevas herramientas comunicativas como verdaderas máquinas de sobrevivencia de creencias mágicas primitivas que llegan hasta nuestros días en un devenir histórico, cultivadas por mentes astutas que han visto en ellas un negocio tan fácil como fructífero (Alonso \& Cortiñas, 2014; Sagan, 2000). Falacias que dolosamente inducen a error al manipular emociones como la esperanza, el miedo y la ingenuidad, mimetizándose incluso como ciencia, de cuyos términos y conceptualizaciones busca aprovecharse y usurpar, deliberadamente. En la medida en que fenómenos esotéricos y mágicos no son demostrables científicamente, todo conjunto de conocimientos sobre esta realidad particular es conceptuado como no científico o, en el mejor de los casos, "pseudociencias". De tal manera, el estudio de la percepción extrasensorial, la clarividencia, la comunicación con los muertos o los actos de adivinación no encajan dentro de los modelos teóricos estándar aceptados por las ciencias, pese a que en sus indagaciones hagan uso de sofisticado instrumental técnico o de metodologías experimentales (Martín, 2016). La ausencia de verosimilitud y contrastabilidad de sus enunciados, la nula evidencia confirmatoria, así como la dificultad para demostrar la existencia de dichos fenómenos paranormales en condiciones controladas de laboratorio, imposibilitan la obtención de la credencial científica de que presumen conjuntos de creencias como la numerología, astrología, parasicología, ufología, por mencionar algunas.

La astrología, creencia que sostiene la influencia de los astros sobre la personalidad, es parte constituyente de la visión mágica que se profesaba antiguamente sobre el mundo (Daxelmüller, 2009). Se pensaba que los cuerpos celestes eran morada y señales de los dioses, íntimamente relacionados con los sucesos de la Tierra; creencia que ha derivado en el sostener que su posición al momento del nacimiento presagia nuestro futuro y ejerce poderosa influencia sobre nuestro carácter y forma de ser, determinando incluso el nivel de sintonía o compatibilidad en la relación que establecemos con otras personas. Pese a no haber fundamento científico para tal creencia, incluso existir poderosa evidencia que la refuta, se observa una favorable recepción de la astrología y otras técnicas de adivinación en los chilenos consultados, siendo sostenida por el $38.2 \%$ de ellos. Entre quienes manifiestan un mayor grado de convicción respecto de que es posible predecir el futuro mediante el acto de adivinación, sea por la lectura del Tarot, el horóscopo y las cartas, destacan quienes son mujeres (42.4\%), menores de 30 años (44.4\%) y que tienen menor escolaridad (40\%).

Resulta paradójico como se disemina la ancestral creencia en la astrología y lectura del horóscopo, a pesar de que gran parte de los cuerpos celestes, supuestamente regentes, se limitan todavía a los conocidos por Tolomeo en el siglo II, ignorando la enorme variedad de nuevos objetos astronómicos descubiertos desde entonces. Contraargumento al que se suma la constante ausencia de correlación entre lo presagiado por el horóscopo y las características de personalidad que de él se derivan por los test psicométricos más reputados. Esta alta e incondicional aceptación, que científicos miran con desconcierto y preocupación, reportaría que estas creencias, por muy infundadas e irracionales que sean, establecen un vínculo emocional con las personas y sus necesidades, poniendo en cuestión el rol mismo de la ciencia y su capacidad divulgativa (Martín, 2016; Sagan, 2000; Tarnas, 2006).

Operar dentro de esquemas cognitivos amparados en pautas preestablecidas por la tradición supone poco esfuerzo, además de una recompensa inmediata (Iglesias, 2012), 
de allí el éxito que tienen las explicaciones simples a fenómenos complejos instaladas por la costumbre, las cuales permanecen a pesar de la nula evidencia que las sustenta. Establecida por la necesidad de creer, no precisa de razones para perdurar, pues se sostiene en un vínculo emocional con nuestra debilidad, fugacidad e intrascendencia. Frente a la presión de la realidad y lo escasamente reconfortante que resulta la incertidumbre, nos volvemos crédulos, aceptando ideas irracionales que llenan el vacío emocional que la ciencia no ha podido colmar $\mathrm{y}$ es fuertemente explotado por un conjunto de pseudoprofesionales dedicados al negocio de esoterismo (Sagan, 2000; Shermer, 2008).

Por otra parte, en ocasiones, las creencias irracionales suelen verse corroboradas $y$ justificadas por el prejuicio de confirmación. En efecto, la percepción de incontrolabilidad de los eventos, así como las coincidencias fortuitas entre estos y la creencia infundada, sostienen y fomentan la conducta supersticiosa (Guerrero et al., 2008). La numerología, en tanto esfuerzo por descubrir en los números información que pueda estar vinculada a lo que se quiere apoyar, es un claro ejemplo de ello. Amparada en las probabilidades y la selectividad de la memoria, lleva a que los sujetos piensen erróneamente que hay números que no se deben usar y otros, que por el contrario, son beneficiosos y traen fortuna (Shermer, 2008). Esta creencia en Chile es compartida por la mitad de los encuestados (50.4\%), encontrándose reducidas diferencias porcentuales entre los grupos de segmentación, siendo la más abultada la establecida entre teístas $(51.7 \%)$ y agnósticos $\left[46 \%\left(\operatorname{EXP}_{(\beta)}=0.8 ; p<\right.\right.$ 0.01)].

En continuidad a la alta prevalencia que tienen el conjunto de ideas infundadas antes exploradas, los datos informan que en lo que respecta a la existencia de naves espaciales que vienen de otros planetas, un $59.9 \%$ de los chilenos manifiesta algún grado de convicción y uno de cada tres cree abiertamente (35\%). Creencia que es más susceptible en hombres $\left[65.3 \% ;\left(\operatorname{EXP}_{(B)}=1.32 ; p<0.01\right)\right]$, en sectores urbanos $\left[63.2 \% ;\left(\operatorname{EXP}_{(\beta)}=1.38 ; p<0.01\right)\right]$, en personas con mayor escolaridad $\left[68.3 \%\right.$; $\operatorname{EXP}_{(\beta)}$
$=1.55 ; p<0.01)]$ y que manifiestan posturas contrarias al principio de comprobabilidad $\left[65.2 \% ; \quad\left(\operatorname{EXP}_{(\beta)}=1.32 ; p<0.01\right)\right]$ Aunque la existencia de vida extraterrestre pudiese sostenerse como probabilidad, la profusa evidencia acumulada referente al avistamiento de OVNIS es altamente cuestionable. Si bien algunos de los relatos pudiesen haberse emitido con sinceridad, lo informado como verdadero avistamiento no pasaba de ser, aunque poco habituales, fenómenos naturales. En efecto, se cometen errores por ingenuidad, precipitación o miopía; se fuerza dolosamente la verdad para ganar dinero, atención o fama; se entiende mal, en ocasiones, lo que se ve, llegando incluso a ver cosas donde no están. La necesidad de creer puede nublar nuestra capacidad de juicio y la emocionalidad nos convierte en malos testigos de lo experimentado. Todo ello lleva a equívoco, donde el medio de prueba para develar la falacia se constituye en valor fundamental. La prueba, como resultado de una experiencia no circunstancial ni única, debe ser irrecusable, y cuanto más se desea que algo sea verdad más cautelosos debemos ser en su aplicación (Sagan, 2000).

\section{El arraigo de la creencia en tiempos modernos}

Los datos informan que aún no nos hemos despojado de las desconcertantes, irracionales e infundadas concepciones del pasado. Muy por el contrario, estas ideas están fuertemente arraigadas y se instalan en un contingente cada vez más grande de personas, por lo que el interés y la preocupación por el estudio de las ideas irracionales o creencias infundadas no resulta ser meramente conceptual, sino que persigue también un fin práctico y de naturaleza ética. La fe y la confianza inquebrantable en la creencia infundada corrompe la cultura y desvirtúa la ciencia, cuyo estatus busca usurpar, poniendo en peligro la búsqueda de la verdad (Bunge, 2010). La creencia irracional, convertida en dogma, es socialmente peligrosa porque, en un proceso de acumulación de fuerzas, todo le está moralmente permitido. En tal estadio, castiga 
y aísla la disidencia que pone en cuestión las ideas especulativas de las cuales se nutre. Más allá del fanatismo religioso como corolario de la creencia infundada llevada a ultranza con las consecuencias ya conocidas, la confianza ciega depositada en lo extraordinario y en lo paranormal vulnera la salud y la economía de la persona y la familia que las profesa, rompe el pacto social cuando se instala como dogma oficial imponiendo un canon de comportamiento determinado que, llevado al extremo, proscribe derechos sociales (Alonso \& Cortiñas, 2014; Bunge, 2010; Gámez, 2015; García, 2015).

Argumentar racionalmente porqué estas creencias, incluso las sostenidas por la pseudociencia con su aura de aparente sistematicidad, son infundadas, pareciera no ser suficiente. Sus partidarios, operando desde el dogma, el principio de autoridad revelada y el comportamiento de secta, parecen ser inmunes al peso de la prueba, al argumento racional, incluso no se dejan seducir por la divulgación científica. $\mathrm{Al}$ aferrarse en la promesa irreal de una vida mejor, en la esperanza fatua de una prolongación, en lo rentable que resultan las pseudorrespuestas simples a problemas complejos, no tan solo se deambula en la ignorancia, sino que rápidamente se adscribe a la intolerancia, lo que pone en cuestión la premisa de la inocuidad de la creencia irracional e infundada. En consecuencia, con el objeto de controlar su diseminación viral, pareciera cada vez más necesaria la ridiculización explícita y directa, como estrategia para desenmascarar lo risible de ellas, tal y como desde el ateísmo militante se sostiene respecto de la existencia de Dios.

\section{Conclusión}

Las creencias configuran parte de la realidad y del mundo que los seres humanos compartimos, algunas de las cuales sirven para sostener explicaciones acerca de fenómenos desconocidos. La vida social, tal y como la conocemos, es atravesada por numerosas visiones acerca de lo real, por ella fluyen distintas explicaciones respecto del cómo y por qué suceden las cosas, en su mayoría denominadas dentro de lo científico o no científico. Mientras las primeras tienen una raigambre teórica clara, una conceptual definida y un método riguroso, las segundas tienen un carácter informal, poco delimitado respecto a las reglas utilizadas en cada conclusión, especialmente abocadas a campos del saber espiritual, astrológico y adivinatorio. Por su persistente mantenimiento en la conciencia colectiva, este segundo tipo de conocimiento o de saberes resulta interesante de abordar, máxime con los cambios culturales acaecidos los últimos 30 años en Chile, donde la irrupción de las tecnologías ha puesto de manifiesto su inconsistencia, en más de una ocasión.

Con base en la información proporcionada por la Encuesta nacional de percepción social de la ciencia y la tecnología (EPSCYT), aplicada en Chile el año 2016 por la Comisión Nacional de Investigación Científica y Tecnológica (CONICYT), este artículo exploró las creencias que tienen los chilenos y chilenas en la llamada pseudociencia, y cómo estas se manifiestan según atributos sociodemográficos.

En términos generales, la población mayoritariamente adscribe que lo único cierto es aquello que se puede comprobar (73.6\%), dando cuenta de un sistema cognitivo que reconoce el importante peso de la prueba para validar las ideas y creencias que se sostienen, adhesión a estructuras de pensamiento hipotéticodeductivo menos sensibles a la seducción que genera el principio de autoridad. No obstante, contradictoriamente, también manifiestan, con diversos grados de certeza, la creencia en la existencia de los milagros (79\%), de los espíritus (65\%), la telepatía $(60.2 \%)$, la adivinación (38.8 $\%)$, la numerología (50.4\%) y los OVNIS (59.9 $\%)$.

$\mathrm{Al}$ respecto, aparecen al menos dos paradojas. La primera, y más obvia, es que aun con el extenso desarrollo y difusión que las ciencias formales han hecho respecto del cómo y por qué ocurren algunos fenómenos, persiste en la sociedad gran cantidad de personas que sostiene creencias infundadas, irracionales, que en contextos de modernidad se considerarían 
superadas o en franca decadencia. Si bien esto podría estar vinculado con escaso acceso a fuentes de información, el uso de las TIC en la población se ha masificado de tal forma que hace insostenible tal acusación; de hecho, son los medios de comunicación de masas los que mayormente sirven de palestra para producir, distribuir y consumir incertidumbres. La segunda es que, aun cuando en la población chilena se ha ampliado la presencia de factores teóricamente protectores para la credulidad, a saber, mayores niveles de escolaridad, urbanización, menos dependencia religiosa y adscripción a la tesis de la comprobabilidad, tales creencias infundadas conviven con las provistas por la ciencia.

Los datos evidencian que las creencias infundadas constituyen una dimensión importante en la vida del sujeto, más general y arraigada de lo que estaríamos dispuestos a reconocer, dado el vertiginoso avance científico y posicionamiento tecnológico en la vida moderna. Sistema de creencias que, en un contexto de pluralismo y libertad, se nutre de una amplia gama de representaciones provenientes del pensamiento mágico, las que ofrecen sentido, cobijo y certidumbre, en un contexto donde la institucionalidad demuestra cierta ineficacia para responder al sentimiento de desesperanza y vulnerabilidad de sus ciudadanos.

Búsqueda de sentido que es hábilmente amplificada por los medios de comunicación y redes sociales que difunden de forma masiva, irresponsable e incluso dolosamente, una significativa cantidad de información errónea, circunstancial e incompleta. Afán inescrupuloso y a veces mercantil que saca provecho de la ingenuidad y necesidad de creer que tienen los sujetos, a lo que se suman intrincados mecanismos psicológicos como los errores de percepción y selectividad de la memoria que releva y generaliza el evento casual y anecdótico.

En lo fundamental, la ciencia nos informa que existimos en un universo menos caótico de lo aparente y que los fenómenos poseen una explicación, aun cuando esta no haya sido descubierta. En consecuencia, la ciencia, en su afán de la búsqueda de la verdad, no solo le atañe la responsabilidad de correr las fronteras del conocimiento, sino que además divulgar de forma clara y comprensible estos hallazgos al gran público no iniciado, reduciendo la brecha o distancia cognoscitiva entre el conocimiento popular y el especializado, tanto para superar el estado de ignorancia, como para deshacer sistemas de creencias infundadas que, dada su capacidad de propagación, resultan menos inocuas de lo que en primera instancia suele suponerse.

\section{Limitaciones del estudio y proyección}

La encuesta nacional de percepción social de la ciencia y la tecnología (EPSCYT) del año 2016 se constituye en la primera experiencia aplicada a nivel nacional, tendiente a explorar las percepciones y apropiaciones que tiene la ciudadanía sobre creencias en CyT. Futuras aplicaciones proyectadas posibilitarán contar con mejores índices e indicadores que establezcan la evolución en el tiempo de estos fenómenos, la caracterización de grupos y definición de nuevas y más refinadas estrategias para la divulgación del conocimiento científico y creencias basadas en evidencias. Las sucesivas aplicaciones de la encuesta y sus correspondientes ajustes permitirán profundizar esta línea de investigación y utilizar modelos estadísticos más robustos para el análisis. Modelos de series de tiempo y diseños multivariantes superarían las limitaciones asociadas al análisis descriptivo del espacio bivariante, de manera a atender cabalmente la complejidad de estos fenómenos perceptivos.

Un mayor conocimiento y experiencia en el estudio de las creencias impulsarán el refinamiento de ítems e incorporación de nuevos reactivos en encuestas ad hoc a grandes muestras, cuyo análisis estadístico requiere ser ampliado y profundizado mediante enfoques cualitativos que brinden una comprensión contextualizada.

\section{Agradecimientos}

Esta investigación fue elaborada por el Centro de Investigación CIDCIE de la Universidad del Bío- 
Bío y pertenece a la línea de desarrollo "Sociedad, Educación y Tecnología de la Información”.

\section{Referencias}

Alonso, F., \& Cortiñas, S. (2014). La pseudociencia y el poder de los medios de comunicación. La problemática ausencia de bases teóricas para afrontar el fenómeno. Historia y Comunicación Social, 19, 93-103. https://doi.org/10.5209/rev_HI CS.2014.v19.45111

Bauman, Z., \& Bordoni, C. (2016). Estado de crisis. Barcelona: Paidós.

Beck, U. (2009). El dios personal. La individualización de la religión y el espíritu del cosmopolitismo. Madrid: Paidós.

Blanco, H., Ornelas, M., Aguirre, J. F., \& Guedea, J. C. (2012). Autoeficacia percibida en conductas académicas. Diferencias entre hombres y mujeres. Revista Mexicana de Investigación Educativa, 17(53), 557-571. Recuperado de http://scielo.unam.mx/pdf/r mie/v17n53/v17n53a11.pdf

Bunge, M. (2010). Las pseudociencias iVaya timo! Pamplona: Laetoli.

Castilla, C. (2011). Rezar para sanar: el recurso mágico-religioso en la búsqueda de la salud. Revista de Humanidades, 18, 109-124. Recuperado de http://revistas.uned.es/inde x.php/rdh/article/viewFile/12882/11959

Cornejo, M. (2011). Perspectivas cognitivas sobre la religión: Neointelectualismo y ontologización de la creencia religiosa en dos naturalismos enfrentados. Intersecciones en Antropología, 12, 95-108. Recuperado de https://www.redalyc.org/pdf/1795/17952 2601008.pdf

Damisch, L. (2008). Keep your fingers crossed!. The influence of superstition on subsequent task performance and its mediating mechanism (Tesis doctoral no publicada). University Zu Köln, Alemania.

David, D., Lynn, S. J., \& Ellis, A. (2010). Rational and irrational beliefs. Research, theory and clinical practice. Nueva York: Oxford University Press.
Daxelmüller, C. (2009). Historia social de la magia. Barcelona: Herder.

Fidanza, J., \& Suárez, A. (2016). Diversidad de creencias, devociones y prácticas religiosas en los asentamientos precarios de la Ciudad de Buenos Aires. Religião $\&$ S Sociedade, 36(1), 103-127. https://doi.org/10.1590/01 00-85872016v36n1cap05

Frigerio, A., \& Wynarczyk, H. (2013). La diversidad religiosa en Argentina: un desafío a la ciencia normal. Cultura y Religión, 7(1), 3-9. Recuperado de https://ri .conicet.gov.ar/handle/11336/27405

Gámez, L. A. (2015). El peligro de creer. Madrid: Léeme Libros.

Garces, M. (2017). Nueva ilustración radical. Barcelona: Anagrama.

García, R. (2015). Pseudociencia en el mundo contemporáneo. Alambique, 81, 25-33. Recuperado de http://bohr.inf.um.es/miembros/rgm/Te achPubl/GarciaMolina PseudocienciaMun doContemporaneo(2015).pdf

Guerrero, C., Ávila, R., \& Miranda, P. (2008). Correlación entre creencias mágicas y variables sociodemográficas. Psicología y Ciencia Social, 10(1), 5-15. Recuperado de http://www.redalyc.org/pdf/314/314148 01001.pdf

Gutiérrez, J. (2007). Ciencia frente a pseudociencia. Revista de Comunicación Vivat Academia, 90, 1-34. https://doi.org/10 $.15178 /$ va.2007.90.1-34

Iglesias, L. (2012). Ciencia y pseudociencia: imposturas y refutaciones (Tesis de maestría no publicada). Madrid, España. Recuperado de http://e-spacio.uned.es/fez/ view/bibliuned:masterFilosofiaLogica-Laigl esias

Martín, P. (2016). Astrología: la creencia en la unión del ser humano y el cosmos (Tesis de doctorado no publicada). Murcia, España. Recuperado de https://digitum.um.es/xmlui/bitstream/1 0201/51619/1/0\%20Tesis\%20PJMARTIN Antropologia_FINAL\%20.pdf

Medrano, L., Galeano, C., Galera, M., \& Fernández, R. (2010). Creencias 
irracionales, rendimiento y deserción académica en ingresantes universitarios. LIBERABIT, 16(2), 183-192. Recuperado de http://revistaliberabit.com/es/revistas/R LE_16_2_creencias-irracionales-rendimien to-y-desercion-academica-en-ingresantesuniversitarios.pdf

Meléndez, R. (2016). La creencia religiosa y la forma de vida del creyente. Ideas y Valores, 65(Supl. 2), 81-93. Recuperado de http://www.scielo.org.co/pdf/idval/v65s2 10120-0062-idval-65-s2-00081.pdf

Molina, A. (2019). El combate contra las fake news: intelectuales en la era de la posverdad. Astrolabio: Revista Internacional de Filosofia, 23, 9-20. Recuperado de https://www.raco.cat/index.php/Astrola bio/article/view/359246

Murillo, M. (2012). El mayor amigo o enemigo del patrimonio arqueológico: El proceso de investigación. Herencia, 25(1-2), 25-32. Recuperado de https://revistas.ucr.ac.cr/in dex.php/herencia/article/view/9934/9346

Orea, M. C. (2013). Supervivencia del pensamiento mágico y mítico en la publicidad de artículos personales: el caso del shampoo. Razón y Palabra, 18(84), 336-342. Recuperado de http://www.razonypalabra.org.mx/N/N8 4/V84/07 Orea V84.pdf

Sagan, C. (2000). El mundo y sus demonios. Barcelona: Planeta.

Shermer, M. (2008). Por qué creemos en cosas raras. Pseudociencia, superstición y otras confusiones de nuestro tiempo. Barcelona: Alba.

Suárez, A. (2016). Devociones, promesas y milagros. Aproximación a dimensiones de la espiritualidad en sectores populares. Ciencias Sociales y Religión, 18(24), 54-70. Recuperado de http://www.seer.ufrgs.br/in dex.php/CienciasSociaiseReligiao/article/vi ew/57841/38441

Tarnas, R. (2006). Cosmos y psique: indicios para una nueva visión de mundo. Gerona: Atalanta.

Taylor, A., \& Kowalski, P. (2004). Naïve psychological science: The prevalence, strength and sources of misconceptions. Psychological Record, 54, 15-25. Recuperado de http://opensiuc.lib.siu.edu/tpr/vol54/iss1 12

\section{Notas}

* Artículo de investigación. 